\title{
PRESIDENT'S REPORT 2020
}

Committee Changes: The IMS committee had a change of Treasurer, with Goetz Pfeiffer (NUIG) being replaced by Cónall Kelly (UCC). Many thanks to the outgoing Treasurer for his years of excellent work in securing the Society's finances. I welcome Ronan Flatley (MIC), Ray Ryan (NUIG), Helena Smigoc (UCD) and Nina Snigireva (NUIG) to the committee and I thank Paul Barry (WIT), Rupert Levene (UCD), Anca Mustata (UCC) and James O'Shea (DCU) who left the committee after years of dedicated work to the Society.

IMS Bulletin: I extend the Society's continuing thanks to Tony O'Farrell for his work as Editor of the Bulletin and I also thank the editorial board of the Bulletin. We are also grateful to Michael Mackey for his considerable work in managing the Society's webpages.

IMS meetings: The Society's 2020 annual "September Meeting", which was scheduled to take place in Dublin City University, August 27-28, 2020 was, like countless other events, postponed due to the coronavirus pandemic. It will now take place online January 13-15, 2021, with sessions on Wednesday and Thursday afternoon (1.30pm $5 \mathrm{pm})$ and Friday morning $(9.30 \mathrm{am}-12.30 \mathrm{pm})$. A number of the talks are linked by the theme of epidemiological and environmental modelling. Sincere thanks to Brien Nolan and Niamh O'Sullivan for organising this conference under challenging circumstances and to DCU for hosting.

The Society's 2021 annual conference is due to take place in Cork, hosted by UCC and MTU. Many thanks to Cónall Kelly and J.P. McCarthy for stepping in to organise the 2021 conference at short notice.

IMS Conference Support: Due to the Covid-19 pandemic, there were no requests for conference support in 2020. Thanks to our treasurer, Cónall Kelly, for managing our finances.

Other: The European Mathematical Society 'Meeting of Presidents' due to be held at CIRM, Luminy, Marseille on March 14-15, 2020 was cancelled, days beforehand, due to the coronavirus pandemic.

International Mathematical Union: The Royal Irish Academy communicated in late 2019 that it would no longer fund Ireland's participation in the International Mathematical Union (IMU) for 2020 or thereafter. The committee of the Irish Mathematical Society therefore agreed that the Society should take over as the adhering body for Ireland to the International Mathematical Union. This transfer was completed in late February 2020. While a process of seeking private sponsorship had begun, it had to be postponed due to the Covid-19 pandemic and lockdown. Contact made with the then Minister for Education, Joe McHugh, during months of a long government formation process, was unproductive. The Society therefore had to seek emergency funding for Ireland's 2020 IMU membership fees of $€ 2,860$. We are sincerely grateful to the following institutions and their directors for their immense generosity in contributing to Ireland's 2020 IMU Fees, which were paid in September 2020: 
- The Boole Centre for Research in Informatics at UCC and Prof. John Morrison;

- The Hamilton Mathematics Institute at TCD and Prof. Samson Shatashvili;

- The Maynooth Hamilton Institute at MU and Prof. Ken Duffy;

- The SFI Connect Research Centre at Waterford IT and Prof. Brendan Jennings;

- The Department of Mathematics and Statistics at UL and Professors James Gleeson and Sarah Mitchell;

- The School of Mathematics and Statistics at UCD and Prof. Ted Cox;

- The Irish Mathematical Society.

The Society aims to seek more sustainable funding, ideally from government, for the longer term.

Closing Comments: I feel immensely privileged to have served as President of the Irish Mathematical Society; even more so, to have served as the first woman President. I sincerely thank the members of the Society for this opportunity. I am grateful to my fellow officers, David, Tom and Cnall, and earlier Goetz, and the rest of the committee for their support and co-operation.

I am delighted to leave behind a committee for 2021 that is almost gender balanced, with five women to seven men. I welcome to the 2021 committee, Romina Gaburro (UL), Ireland's contact for 'European Women in Mathematics' and also Ann O'Shea (MU), who will chair our newly established 'Irish Committee for Mathematics Education', which comprises more women than men. I am proud that the Society has endorsed an open letter from 'European Women in Mathematics' on 'Corona Crisis: Impact on junior and women mathematicians' and also of the multi-institutional Athena Swan initiative in the mathematical sciences being led by Niall Madden of NUIG. These are all welcome trends that I hope will continue.

Pauline Mellon,

December, 2020.

E-mail address: pauline.mellon@ucd.ie 